Article

\title{
Knowledge and Prior Use of HIV Self-Testing in Madrid and Barcelona among Men Who Have Sex with Men More than One Year after Its Legal Authorization in Spain
}

\author{
Juan-Miguel Guerras 1,2 ${ }^{(D}$, María-José Belza ${ }^{2,3, *}$, María-José Fuster ${ }^{4,5}$, Luis de la Fuente ${ }^{1,2}$, \\ Patricia García de Olalla ${ }^{2,6}$, David Palma ${ }^{2,6}{ }^{\mathbb{D}}$, Jorge-Néstor García-Pérez ${ }^{7}$, Juan Hoyos ${ }^{8}$ \\ and on behalf of the Methysos Project Group ${ }^{+}$
}

check for updates

Citation: Guerras, J.-M.; Belza, M.-J.; Fuster, M.-J.; Fuente, L.d.l.; García de Olalla, P.; Palma, D.; García-Pérez J.-N.; Hoyos, J.; on behalf of the Methysos Project Group. Knowledge and Prior Use of HIV Self-Testing in Madrid and Barcelona among Men Who Have Sex with Men More than One Year after Its Legal Authorization in Spain. Int. J. Environ. Res. Public Health 2022, 19, 1096. https:// doi.org/10.3390/ijerph19031096

Academic Editor: Paul B. Tchounwou

Received: 22 November 2021

Accepted: 14 January 2022

Published: 19 January 2022

Publisher's Note: MDPI stays neutral with regard to jurisdictional claims in published maps and institutional affiliations.

Copyright: (c) 2022 by the authors Licensee MDPI, Basel, Switzerland. This article is an open access article distributed under the terms and conditions of the Creative Commons Attribution (CC BY) license (https:// creativecommons.org/licenses/by/ $4.0 /)$.
1 Centro Nacional de Epidemiología, Instituto de Salud Carlos III, 28029 Madrid, Spain; jguerras@isciii.es (J.-M.G.); Ifuente@isciii.es (L.d.l.F.)

2 CIBER Epidemiología y Salud Pública (CIBERESP), 28029 Madrid, Spain; polalla@aspb.cat (P.G.d.O.); ext_dpalma@aspb.CAT (D.P.)

3 Escuela Nacional de Sanidad, Instituto de Salud Carlos III, 28029 Madrid, Spain

4 Sociedad Española Interdisciplinaria del SIDA, SEISIDA, 28036 Madrid, Spain; mjfuster@psi.uned.es

5 Departamento de Psicología Social y de las Organizaciones, Universidad Nacional de Educación a Distancia, 28040 Madrid, Spain

6 Servicio de Epidemiología, Agència de Salut Pública de Barcelona, 08023 Barcelona, Spain

7 Unidad de ITS de Vall d'Hebron-Drassanes, Hospital Vall d'Hebron, 08001 Barcelona, Spain; g.perez@vhebron.net

8 Independent Researcher, 28013 Madrid, Spain; hoyosmiller@hotmail.com

* Correspondence: mbelza@isciii.es

+ Collaborators/Membership of the Group is provided in the Supplementary Material; Methysosprojectgroup@hotmail.com.

Abstract: This study assessed the knowledge and prior use of HIV self-testing in a sample of men who have sex with men (MSM) recruited in a sexual health clinic and two community-based testing sites in Madrid and Barcelona, >12 months after its legal authorization. Between March 2019 and December 2020, we recruited 2044 MSM. Participants completed a self-administered questionnaire while waiting to be tested for HIV and other STIs. We built two Poisson regression models to assess factors associated with prior knowledge and with use. Among those who had used self-testing in the past we assessed frequency of use and several aspects related to the last testing episode. The proportion of participants that knew about the existence of self-testing and had already used it was of $26.3 \%$ and $5.1 \%$ respectively. Both, knowledge and use were independently associated with being born in Spain or other western European countries, university education and more recent HIV testing. Additionally, knowledge was associated with older age, having a more favorable economic situation, and not living sexuality in total secrecy. Use was also associated with having received money in exchange for sex. Most (69.5\%) reported having self-tested once, $64.8 \%$ had self-tested $<12$ months ago, $63.8 \%$ self-tested alone and $71.4 \%$ acquired the kit at a pharmacy over the counter. In spite of its authorization and becoming legally available, knowledge and use of HIV self-testing remain low among MSM attending sites specialized in the diagnosis of HIV and other STIs. When designing scale-up strategies, lower levels of knowledge and use in less favored subgroups of MSM need to be factored in.

Keywords: early diagnosis; HIV self-testing (HIVST); men who have sex with men (MSM)

\section{Introduction}

HIV remains an important public health concern in Western Europe. In Spain, as in the rest of Western Europe, men who have sex with men (MSM) are the group most affected by the epidemic. In 2019, 2.698 new cases of HIV were reported to the Spanish 
HIV surveillance system, of which $56.6 \%$ were acquired through sex between men [1]. One of the main strategies to fight the epidemic is to identify new infections and initiate treatment as early as possible. Early diagnosis and treatment allow individuals to fully benefit from highly active antiretroviral therapy (HAART) by reducing morbidity [2,3] and mortality [4]. Additionally, early detection and HAART initiation are also important as a way of controlling the expansion of the epidemic since HAART greatly reduces the probability of transmission by reducing viral load [5,6]. Promoting early diagnosis and treatment are in fact two of the keystones of the 95-95-95 UNAIDS fast track strategy to end the epidemic. According to it, by $2030,95 \%$ of all individuals living with HIV should be diagnosed, $95 \%$ of which should be on treatment and $95 \%$ of these should achieve viral suppression [7].

In Spain, HIV testing is offered free of cost at all levels of the national health system and it can also be found anonymously in a network of Sexual Health Clinics [8]. HIV rapid testing is also offered outside clinical settings and can be found in community-based organizations (CBO) [9] and community pharmacies in some regions [10]. However, testing frequency of MSM living in Spain [11] is far from meeting the recommendation of testing at least each 12 months [12]. In fact, $41.3 \%$ of the new cases of HIV reported among MSM in 2019 were diagnosed at a late stage of infection (CD4 count of $<350 \mathrm{~mm}^{3}$ ) [1]. HIV self-testing, is the most recent testing methodology that has been added to already existing options. In Europe, the United Kingdom authorized HIV self-testing for public use in 2014 and since then it has spread to other European countries [13,14]. In Spain, it has been legally commercialized since December 2017 [14,15]. HIV self-testing requires the user to take a blood or a saliva-based sample, perform the test and interpret the results. When reactive, self-testing requires confirmation testing. It is considered an accurate testing methodology and is supported by the World Health Organization [16].

HIV self-testing could help remove some of the barriers to testing and increase testing frequency in MSM that do not meet testing recommendations. Compared with traditional on-site testing, self-testing offers increased privacy and anonymity and is highly convenient since it does not require appointments or queuing [17]. According to the opinions of MSM recruited in online gay dating websites and apps in Spain, acceptability and potential use of HIV self-testing is high [18] and it is a highly valued option [19]. In fact, several clinical trials also support self-testing's capacity to increase testing frequency among MSM and other highly vulnerable populations $[20,21]$ but there is little real-life data on its capacity to promote testing. This is challenging since HIV statistics do not reflect the setting where HIV testing is occurring. One way of overcoming this limitation is through self-reported data. In this sense, outcomes related to knowledge and prior use of self-testing are important ways of overcoming this surveillance limitation and to gauge the capacity of this still relatively new testing option to promote testing and increase testing frequency among MSM.

Knowledge and prior use have been previously assessed in Spain. A study conducted between 2010-2012 among attendees of a rapid testing program run by a community-based organization [22], showed low knowledge (5.3\%) and near-to-zero (0.6\%) use of HIV selftesting. Similarly, an online-based study conducted during 2012 and 2013, reported that under $5 \%$ of the participant MSM knew about the existence of self-testing and less than 1\% had used it [23]. Another online-based study conducted in MSM in 2016, reported higher knowledge levels (14.5\%) [24] but still very low use (1.5\%). This same study also presented data on knowledge and use for seven other countries: Belgium, Denmark, Germany, Greece, Portugal, Romania and Slovenia. Knowledge ranged from $15.3 \%$ to $35.1 \%$ and prior use from $0.1 \%$ to $4.5 \%$. Finally, knowledge and use were also assessed in a study conducted among MSM in France [25] which presented a level of knowledge of 30\% and a level of prior use of $<1 \%$. However, all the aforementioned studies were carried out before the authorization of self-testing in the studied countries. We only found one study that assessed prior -use (but not knowledge) after the authorization of self-testing. In this study, 9.9\% of participants (mainly MSM) reported having used it in the past [26]. 
Thus, there is roughly no information on how the authorization and subsequent commercialization of self-testing kits can affect both outcomes. This gap needs to be filled in order to understand the level of permeation that self-testing has had in MSM after its authorization and to guide decision makers when designing HIV self-testing strategies. Furthermore, it will help to identify subpopulations in need of interventions to promote knowledge and subsequent use.

In the present study, we recruited a sample of MSM in specialized HIV/STI diagnosis contexts in the cities of Madrid and Barcelona after the authorization of HIV self-testing. We aim to determine the level of knowledge of this testing method in the MSM population and its capacity of promoting HIV testing by evaluating prior use. Additionally, among those who reported having used it in the past we describe the frequency of past use, time since last self-test, and several characteristics related to their last testing episode.

\section{Materials and Methods}

\subsection{Participants}

A total of 2044 participants seeking to be tested for HIV were recruited between March 2019 and December 2020 in the cities of Madrid and Barcelona which are the two largest cities in Spain with 3,334,730 and 1,664,182 inhabitants respectively [27]. In order to be included in the study, participants needed to report having had anal sex with another man at least once in their life and either having a negative result in their last HIV testing episode or not having tested for HIV in the past. HIV-positive individuals, women, men with no previous sexual experience or who reported having had sex exclusively with women were not included in the study. We also did not include individuals under 18 years old.

\subsection{Recruitment and Data Collection Instrument}

Recruitment was carried out in three sites. In Barcelona, it was conducted in the largest sexual health clinic in the city (Drassanes) and in a community-based program run by the Public Health Agency of Barcelona. In Madrid, it was conducted in a community-based program run by the Pink Peace non-governmental association. Sexual health clinics in Spain offer on-demand services and perform traditional testing for all STIs. Community programs, offer rapid testing for HIV, syphilis, and sometimes Hepatitis C. They also carry out active recruitment through ads and profiles inviting users of dating apps to visit their program for testing.

Attendees were approached for participation while waiting to be tested in the recruitment sites. Those who agreed to participate, answered a self-administered online questionnaire on a tablet. The questionnaire included questions that assessed a number of areas including sociodemography, openness, sexual behaviors, history of STI, and history of HIV testing. It also included a section that assessed several aspects related to HIV self-testing including knowledge about the existence of HIV self-testing and prior use which are the two main outcomes of the present paper. Knowledge was assessed with the question "Did you know that in SPAIN for more than a year now, you can buy an HIV self-test in pharmacies and para-pharmacies without needing a prescription?". Participants could choose between three closed response options: No, I did not; I had heard something, but I was not sure; Yes, I knew. Use was assessed with the question "Have you ever been tested for HIV using a self-testing kit". Participants had to answer "yes" or "no". Those who answered having used it in the past, were inquired about the number of times they had used it, time since last use, place of acquisition of last self-testing kit and with whom did he perform the last self-test. The study was approved by the Research Ethics Committee of the Instituto de Salud Carlos III (CEI PI 44_2018_subproyecto1-v2 and CEI PI 44_2018_subproyecto2).

\subsection{Data Analysis}

Our study sample, was comprised of 2044 MSM who answered the questions on knowledge and past use of HIV self-testing. We first performed a descriptive analysis of the 
main characteristics of the sample. Secondly, we estimated the proportion of participants who reported knowledge and past use of HIV self-testing by relevant independent variables. The outcome on the knowledge about the existence of HIV self-testing was collapsed in a two-category variable: (1) Yes; (2) No, I did not; I had heard something, but I was not sure. To estimate the factors associated with knowledge and with past use of self-testing, we used Poisson regression with robust variance in the framework of generalized linear models' analysis [28,29] to calculate the crude and adjusted prevalence ratios (PRs) with their 95\% confidence intervals (CI95\%). We initially included all the relevant variables with a significance level $\leq 0.20$ and employed the minimum Akaike information criterion and the minimum Bayesian Schwartz information criterion for model comparisons and to select the optimal model. Final models were adjusted by age. Finally, for those who reported having used an HIV self-test in the past, we assessed the number of times they had used it, time since last use, place of acquisition and person with who they used it the last time.

\section{Results}

\subsection{Participants' Main Characteristics}

Approximately half (46.4\%) of all participants were recruited in the Madrid communitybased program, 36.2\% were under 30 years of age, 58.0\% were born in Spain, 59.1\% had finished their university education, $58.8 \%$ had a comfortable or good economic situation, and $78.6 \%$ reported living in a city of more than 1,000,000 inhabitants. Approximately six in ten $(61.2 \%)$ reported living their sex life with other men in a completely open manner and $63.2 \%$ reported only having had sex with other men. One in four MSM (25.6\%) reported not having had unprotected receptive anal sex with another man during the last 12 months, $8.9 \%$ reported having paid and $12.4 \%$ reported having been paid for sex. Only $5.8 \%$ reported having had unprotected intercourse with women in the last 12 months. Regarding history of STI, $56.2 \%$ reported a previous diagnosis $(29.3 \%$ during the previous 12 months). Only $6.0 \%$ reported not having been tested for HIV before and $77.1 \%$ had been tested in the previous 12 months (47.6\% in the previous 6 months) (Table 1$)$.

Table 1. Main characteristics of men who have sex with men recruited in Barcelona and Madrid $(n=2044)$.

\begin{tabular}{lcc}
\hline & $n$ & $\%$ \\
\hline Recruitment site & & \\
$\quad$ Madrid community-based program & 949 & 46.4 \\
Barcelona community-based program & 678 & 33.2 \\
$\quad$ Barcelona sexual health clinic & 417 & 20.4 \\
Age & & \\
$\quad<30$ & 740 & 36.2 \\
$30-39$ & 722 & 35.3 \\
$\geq 40$ & 582 & 28.5 \\
Place of birth & & 30.0 \\
$\quad$ Latin America & 613 & 58.0 \\
$\quad$ Spain & 1185 & 7.1 \\
$\quad$ Western Europe & 146 & 4.9 \\
$\quad$ Others & 100 & \\
What is the highest level of education you have & & 7.1 \\
completed? & & 33.8 \\
$\quad$ Up to primary school & 144 & 59.1 \\
$\quad$ Up to upper secondary & 687 & 1203 \\
$\quad$ University education & & \\
\hline
\end{tabular}


Table 1. Cont.

\begin{tabular}{|c|c|c|}
\hline & $n$ & $\%$ \\
\hline \multicolumn{3}{|l|}{ Self-defined economic situation } \\
\hline Difficult/very difficult & 201 & 9.8 \\
\hline Tight & 640 & 31.4 \\
\hline Comfortable/good & 1200 & 58.8 \\
\hline$>1,000,000$ inhabitants of place of residency & 1601 & 78.6 \\
\hline \multicolumn{3}{|l|}{ Lives sex life with other men ... } \\
\hline Hidden/in total secrecy & 122 & 6.0 \\
\hline Discreetly & 669 & 32.8 \\
\hline Openly & 1247 & 61.2 \\
\hline Has had sex only with men (ever) & 1291 & 63.2 \\
\hline \multicolumn{3}{|l|}{$\begin{array}{l}\text { Number of men with whom he had unprotected } \\
\text { receptive anal sex* }\end{array}$} \\
\hline 0 & 447 & 25.6 \\
\hline 1 & 582 & 33.4 \\
\hline $2-4$ & 503 & 28.9 \\
\hline$\geq 5$ & 211 & 12.1 \\
\hline Unprotected intercourse with women * & 119 & 5.8 \\
\hline Has paid for sex* & 181 & 8.9 \\
\hline Has been paid for sex* & 253 & 12.4 \\
\hline \multicolumn{3}{|c|}{ History of sexually transmitted infections diagnosis } \\
\hline No STI diagnosis & 887 & 43.8 \\
\hline STI diagnosis $>12$ months ago & 543 & 26.8 \\
\hline STI diagnosis in the last 12 months & 594 & 29.3 \\
\hline \multicolumn{3}{|l|}{ Time since last HIV test } \\
\hline Never tested before & 123 & 6.0 \\
\hline More than 5 years & 49 & 2.4 \\
\hline $1-5$ years & 296 & 14.5 \\
\hline $6-12$ months & 602 & 29.5 \\
\hline$<6$ months & 972 & 47.6 \\
\hline
\end{tabular}

* In the last 12 months.

\subsection{Knowledge and Past Use of HIV Self-Testing}

Overall, 26.3\% reported knowing about the existence of this testing option and 5.1\% reported having used it in the past.

The proportion of MSM who reported knowing about the existence of HIV self-testing as well as the crude and adjusted PRs are presented in Table 2. Knowledge was higher among participants older than 30 (30-39 years Adj PR = 1.2 (CI95\%: 1.0-1.4); $\geq 40$ Adj PR 1.2 (CI95\%: 1.0-1.5)); those who were born in Spain (Adj PR = 1.8 (C195\%: 1.5-2.2)) or in other western European countries (Adj PR = 1.5 (CI95\%: 1.1-2.1)); those who had completed university education (Adj PR $=1.2$ (C195\%: 1.0-1.4)) and among those who had a comfortable economic situation (Adj PR $=1.4$ (CI95\%: 1.0-1.9)). Compared with men who lived their sex life hidden or in total secrecy, knowledge was higher among those who reported living it discreetly (Adj PR $=1.5$ (CI95\%: 1.0-2.5)) or openly (PR $=1.9$ (CI95\%: 1.2-3.0)). Compared with MSM with no previous HIV testing experience, knowledge was higher among those whose last test was $>5$ years ago (Adj PR $=2.3(\mathrm{CI} 95 \%$ : 1.2-4.7)); 6-12 months ago (Adj PR = 1.8 (CI95\%: 1.1-3.2)) and less than 6 months ago (Adj PR = 2.4 (CI95\%: 1.2-4.7)).

Prevalence of use by relevant independent variables is presented in Table 3. Compared with Latin-American MSM, use was higher among Spaniards (Adj PR = 1.6 (CI95\%: 1.0-2.5)) and those born in other western European countries (Adj PR $=2.4$ (CI95\%: 1.3-4.6)). Use was also higher in those who had completed their university education (Adj PR = 1.5 (CI95\%: 1.0-2.3)), those who reported having been paid for sex (Adj PR $=1.8$ (C195\%: 1.1-2.9)) and among those who received their last test less than six months ago (Adj PR $=2.5$ (CI95\%: 1.4-4.6)). 
Table 2. Proportion of participants who know about the existence of HIV self-testing and associated variables (crude and adjusted prevalence ratios).

\begin{tabular}{|c|c|c|c|c|c|c|c|c|c|}
\hline \multirow{3}{*}{ Total } & \multicolumn{2}{|c|}{ Yes } & \multicolumn{2}{|c|}{ No/Not Sure } & \multirow{3}{*}{ CPR * } & \multirow{3}{*}{$\begin{array}{c}p- \\
\text { Value }\end{array}$} & \multirow{3}{*}{ CI95\% ** } & \multirow{3}{*}{$\mathbf{A P R} * * *$} & \multirow{3}{*}{ CI95\% } \\
\hline & $n$ & $\%$ & $n$ & $\%$ & & & & & \\
\hline & 537 & 26.3 & 1507 & 73.7 & & & & & \\
\hline Recruitment site & & & & & & 2 & & & \\
\hline Madrid community-based program & 226 & 23.8 & 723 & 76.2 & ref & & & & \\
\hline $\begin{array}{l}\text { Barcelona community-based } \\
\text { program }\end{array}$ & 175 & 25.8 & 503 & 74.2 & 1.1 & & $0.9-1.3$ & & \\
\hline Barcelona sexual health clinic & 136 & 32.6 & 281 & 67.4 & 1.4 & & $1.1-1.7$ & & \\
\hline Age & & & & & & 2 & & & \\
\hline$<30$ & 164 & 22.2 & 576 & 77.8 & ref & & & ref & \\
\hline $30-39$ & 201 & 27.8 & 521 & 72.2 & 1.3 & & $1.0-1.5$ & 1.2 & $1.0-1.4$ \\
\hline$\geq 40$ & 172 & 29.6 & 410 & 70.4 & 1.3 & & $1.1-1.7$ & 1.2 & $1.0-1.5$ \\
\hline Place of birth & & & & & & 1 & & & \\
\hline Latin America & 99 & 16.2 & 514 & 83.8 & ref & & & ref & \\
\hline Spain & 375 & 31.6 & 810 & 68.4 & 2.0 & & $1.6-2.4$ & 1.8 & $1.5-2.2$ \\
\hline Western Europe & 44 & 30.1 & 102 & 69.9 & 1.9 & & $1.3-2.7$ & 1.5 & $1.1-2.1$ \\
\hline Others & 19 & 19.0 & 81 & 81.0 & 1.2 & & $0.7-1.9$ & 1.1 & $0.7-7.1$ \\
\hline $\begin{array}{l}\text { What is the highest level of education } \\
\text { you have completed? }\end{array}$ & & & & & & 1 & & & \\
\hline Below university education & 179 & 21.5 & 652 & 78.5 & ref & & & ref & \\
\hline University education & 355 & 29.5 & 848 & 70.5 & 1.4 & & $1.1-1.6$ & 1.2 & $1.0-1.4$ \\
\hline Self-defined economic situation & & & & & & 1 & & & \\
\hline Difficult/very difficult & 33 & 16.4 & 168 & 83.6 & ref & & & ref & \\
\hline Tight & 138 & 21.6 & 502 & 78.4 & 1.3 & & $0.9-1.9$ & 1.1 & $0.8-1.5$ \\
\hline Comfortable/good & 365 & 30.4 & 835 & 69.6 & 1.9 & & $1.3-2.6$ & 1.4 & $1.0-1.9$ \\
\hline Lives sex life with other men ... & & & & & & 1 & & & \\
\hline Hidden/in total secrecy & 16 & 13.1 & 106 & 86.9 & ref & & & ref & \\
\hline Discreetly & 149 & 22.3 & 520 & 77.7 & 1.7 & & $1.0-2.8$ & 1.5 & $1.0-2.5$ \\
\hline Openly & 371 & 29.8 & 876 & 70.2 & 2.3 & & $1.4-3.7$ & 1.9 & $1.2-3.0$ \\
\hline Sex of lifetime sexual partners & & & & & & 3 & & & \\
\hline Men and women & 180 & 23.9 & 573 & 76.1 & ref & & & & \\
\hline Only men & 357 & 27.7 & 934 & 72.3 & 1.2 & & $1.0-1.4$ & & \\
\hline Has been paid for sex (last 12 months) & & & & & & 2 & & & \\
\hline Yes & 51 & 20.2 & 202 & 79.8 & ref & & & & \\
\hline No & 486 & 27.2 & 1304 & 72.8 & 1.3 & & $1.0-1.8$ & & \\
\hline $\begin{array}{l}\text { Unprotected intercourse with women } \\
\text { (last } 12 \text { months) }\end{array}$ & & & & & & 2 & & & \\
\hline Yes & 19 & 16.0 & 100 & 84.0 & ref & & & & \\
\hline No & 518 & 26.9 & 1406 & 73.1 & 1.7 & & $1.1-2.7$ & & \\
\hline Time since last HIV test & & & & & & 1 & & & \\
\hline Never tested before & 13 & 10.6 & 110 & 89.4 & ref & & & ref & \\
\hline More than 5 years & 14 & 28.6 & 35 & 71.4 & 2.7 & & $1.3-5.8$ & 2.3 & $1.2-4.7$ \\
\hline $1-5$ years & 64 & 21.6 & 232 & 78.4 & 2.0 & & $1.1-3.7$ & 1.6 & $0.9-2.8$ \\
\hline $6-12$ months & 149 & 24.8 & 453 & 75.2 & 2.3 & & $1.3-4.1$ & 1.8 & $1.1-3.2$ \\
\hline$<6$ months & 297 & 30.6 & 675 & 69.4 & 2.9 & & $1.7-5.0$ & 2.4 & $1.4-4.0$ \\
\hline
\end{tabular}

The table shows results for variables with a significance level of $\leq 0.20$ in the crude analysis and variables retained in the final model. ${ }^{*}$ Crude prevalence ratio, $* * 95 \%$ confidence interval, ${ }^{* * *}$ adjusted prevalence ratio. ${ }^{1} p$-value $<0.01 ;{ }^{2} p$-value $<0.05 ;{ }^{3} p$-value $\leq 0.20$.

Among those who reported having previously used a self-test, $69.5 \%$ reported having used it only once, $64.8 \%$ used one in the last 12 months and $71.4 \%$ bought the last one over the counter at a pharmacy. Almost two in three (63.8\%) conducted their last self-test alone (Table 4). 
Table 3. Proportion of participants who reported having used a self-testing kit and associated variables (crude and adjusted prevalence ratios).

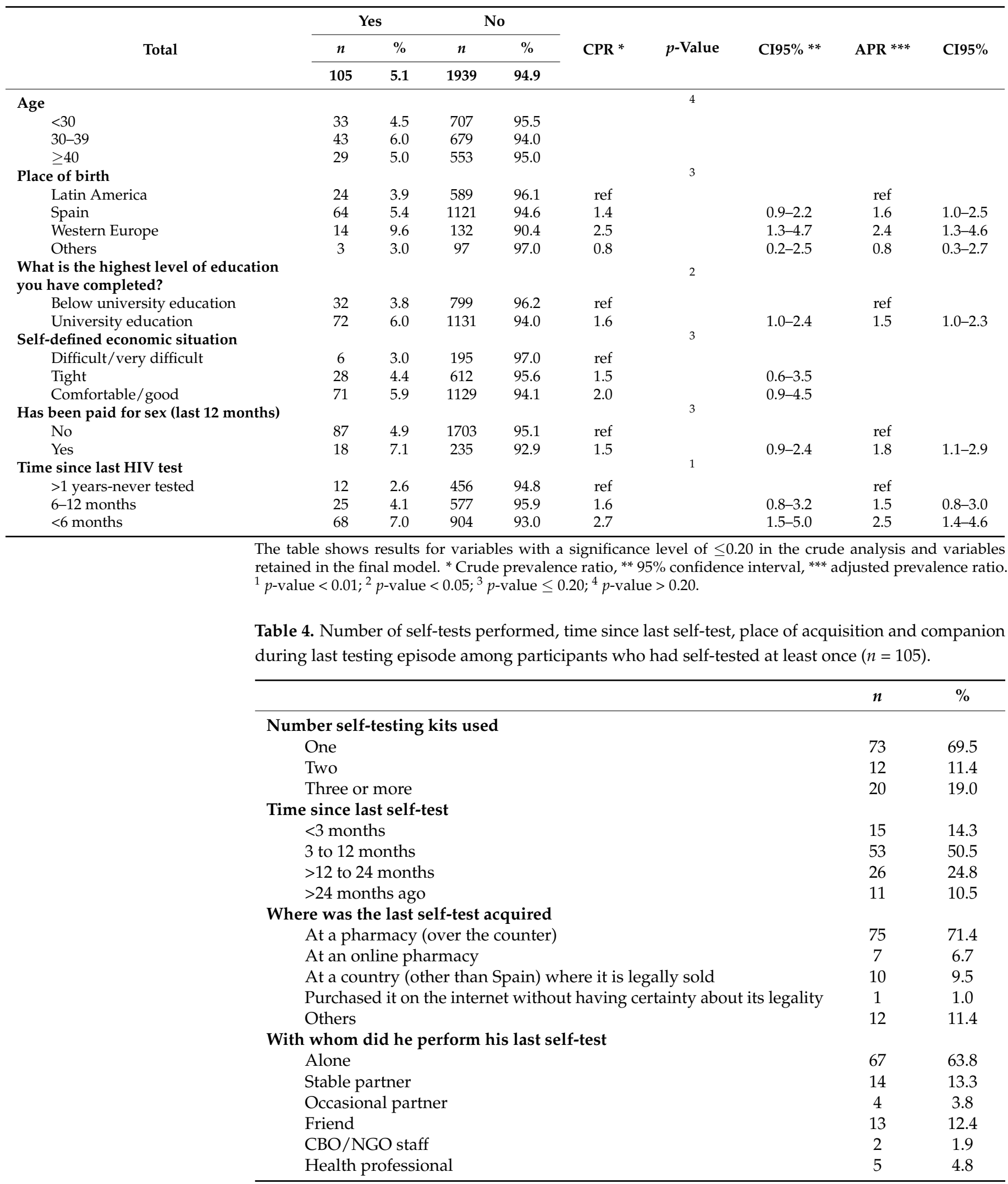




\section{Discussion}

In this sample comprised of MSM recruited at a sexual health clinic and two communitybased counseling and testing programs after the authorization of HIV self-testing, knowledge and use remain low. Higher knowledge was found in older MSM, those born in Spain or in other western European countries, with university education, with a comfortable economic situation, and whose sexual life with other men was not completely hidden. It was also higher among those who reported having been tested before. Prior use was also associated with having been born in Spain or western Europe, having university education and having previous HIV testing experience. Additionally, it was also associated with having been paid for sex in the last 12 months. Self-tests were generally acquired over the counter at pharmacies, use was recent, infrequent and tended to be used alone.

Compared with the studies conducted previously in Spain, the level of knowledge in our sample was nearly two times higher than in the most recent study [24] and approximately five times higher than in the two older studies [22,23]. When compared with other countries, we found that our level of knowledge was slightly lower than in other countries such as France [25], Germany or Belgium [24]. Regarding use, the level of previous use we found in our sample was $>6$ times higher than in the older studies conducted in Spain [22,23] and nearly 3.5 times higher than in the most recent study [24]. When compared with other countries use was $>6$ times higher than in France [25] and at least two times higher than in the rest of the countries assessed in the multi-country study [24] with the exception of Germany where level of use was similar to the one found in our sample. Use was half of that reported by the only study that was conducted after self-testings' legal authorization in France [26].

Differences of knowledge with the studies conducted in Spain could be explained by different population characteristics derived from different recruitment methods (online vs. on site) $[23,24]$. Our sample was comprised of MSM recruited in Madrid and Barcelona both of which are LGBTQIA+ friendly cities. Whether levels of knowledge in smaller cities and rural areas could be different remains unknown but needs to be assessed. These MSM subpopulations-although smaller in size-could face unique barriers to access testing and self-testing could contribute to alleviating them. Having said this, participants who reported living in municipalities of under 1,000,000 inhabitants presented similar knowledge rates and this variable did not reach the necessary $<0.20$ significance in the crude analysis to be considered in the adjusted multivariable model. On the other hand, differences could also be because the recruitment for this study was conducted after the authorization of Self-testing as opposed to the rest of the studies conducted in Spain [22-24].

The higher levels of knowledge found in other European countries [24,25] —where studies were also conducted before the authorization of self-testing - suggest that baseline knowledge at the moment of authorization was lower in Spain than in countries such as Belgium or France. Knowledge is important because it is a necessary condition for use. In Spain, authorization was followed by coverage both in general and gay-oriented media which probably explains the increase in knowledge when compared with previous studies. However, the proportion of participants who knew about it remained low. No specific campaign was conducted at the moment of its authorization by the ministry of health and could be considered at this point if levels of knowledge want to be raised. Other stakeholders such as $\mathrm{CBO} / \mathrm{NGOs}$, clinicians and public health professionals could also play a role in the promotion of self-testing but their position towards this testing option-especially among $\mathrm{CBO} / \mathrm{NGO}$ workers-is less favorable than among MSM mainly because they consider the presence of an expert to counsel and inform about the result to be essential [30].

Knowledge was higher among participants of older age which is a promising result since surveillance data in Spain reports that delayed diagnosis increases with age [1]. High rates of late diagnosis among older individuals suggest that they are in need of alternative testing methods to allow them more frequent testing and earlier diagnosis. However, this association did not hold in the multivariable model for self-testing use, 
suggesting the need to find adequate strategies to transform higher knowledge into higher use in older age groups. Knowledge was also higher among socially favored MSM (i.e., individuals from Spain and other western European countries, with university education and with a comfortable economic situation) which is different from what was found in previous findings in Spain where increased knowledge rates were not found in more favored subgroups [22,23]. This could indicate that self-testing is finding its way into society through higher socioeconomic stratums. Likewise, knowledge was lower among those who lived their sexuality in total secrecy. Not being open about one's sexuality is one of the factors commonly associated with not having been tested for HIV [31-33]. The privacy and anonymity offered by self-testing could facilitate testing to this subpopulation as suggested in other studies [34] and strategies should be put in place to inform them about the existence of a testing approach that allows checking HIV serostatus without disclosing sexual behavior. Finally, knowledge tended to be higher among those who had previous testing history (except for those who reported having received their last test between 1 and 5 years ago). Having been tested in the past has also been found to be associated with knowledge in previous studies [22,23].

Regarding use, only 5\% of our participants reported having used it in the past. This is still a low proportion that needs to be raised in order to make a real contribution in the first "95" of the UNAIDS strategy. However, we need to keep in mind that recruitment started only 15 months after the authorization of HIV self-testing and, as aforementioned, knowledge was still low. In fact, the number of participants that reported more than one self-test is low and last reported use was recent. Similar to knowledge, levels of use of HIV self-testing could be different in MSM living in smaller cities and rural areas and needs to be assessed in samples with a larger presence of these subpopulations. However, in the present study, participants living in municipalities of under 1,000,000 inhabitants, presented similar levels of use. Even if no additional information campaigns are carried out, knowledge will tend to increase through word of mouth and will naturally lead to higher overall use. Further studies should be carried out to identify groups where knowledge is translating into use. This would imply restricting multivariable analyses assessing use to those who already know about the existence of HIV self-testing.

When considering how to increase the use of self-testing, we need to take into account distribution modalities. In our sample, self-testing kits were acquired mainly over the counter in a pharmacy. Promoting web-based distribution strategies could increase convenience even further and according to a recent meta-analysis, increases the probabilities of self-testing uptake [35].

It is important to note that, similar to knowledge, use was lower in some less favored subgroups (i.e., Latin-American migrants, with no university education). When promoting HIV self-testing within these subpopulations, the cost needs to be especially factored in [36]. Currently, the price of self-testing kits is $25-30$ euros. This price could be too high for MSM of lower socioeconomic status. With time, prices could fall due to competition of new selftesting kits introduced in the market by pharmaceutical companies but as of now, if benefits derived from HIV self-testing need to reach less favored subgroups, roll-out strategies need to consider the cost. Programs offering subsidies, discounts, or free distribution of selftesting kits directly targeting immigrants and less socially favored MSM could increase the use of this testing modality and need to be evaluated. Higher use was also reported among those who reported having been paid for sex in the last 12 months which suggests that HIV self-testing is an attractive option for this especially vulnerable population. For male sex workers, HIV self-testing offers the opportunity of checking partners' HIV serostatus before sexual intercourse with a new partner and can be incorporated as an additional tool to bio-behavioral prevention. However, in our sample this type of use was rare with very few participants reporting having used HIV self-testing with their occasional sex partners and most of our participants reported having used it alone. The reasons for not using self-testing kits were not explored although previous works report that aspects such as 
concerns about reliability or fear of not being able to perform a self-test properly are not within the main preoccupations of MSM [24].

Results are not without limitations. When assessing unprotected anal intercourse, we only asked about receptive anal sex which is the role that implies the highest risk for HIV. We do not know if also including insertive anal sex in the assessment of the association between unprotected anal intercourse and the main outcomes could have implied the association of this variable with knowledge and use in the final multivariable models. This is a convenience sample and therefore generalizations to the overall MSM population need to be made with caution. Our sample is consists of individuals residing in large cities of over 1,000,000 inhabitants and is lacking participants living in smaller cities and rural areas that probably face particular barriers to access HIV testing services. There is also a relevant selection bias that needs to be noted: by definition, all participant MSM were searching for an HIV test and therefore knew how to access existing testing services (in this case community-based programs or sexual health clinics). For this study population, self-testing could improve convenience and result in an increase in testing frequency among high-risk individuals. However, it does not include MSM with no previous testing experience or those who are not actively seeking to be tested. It is essential that HIV-testing strategies reach such populations and self-testing could be a way of targeting them. Further studies with different recruitment methods need to be conducted to assess knowledge and use for MSM with no previous testing experience who are not actively seeking an HIV test, and among those living in smaller cities and rural areas. Finally, other studies will also need to be conducted to assess knowledge and use of HIV self-testing in other highly vulnerable MSM not assessed in the present paper such as those involved in sexualized drug use or chemsex [37].

\section{Conclusions}

Knowledge and use of HIV self-testing after the authorization of this testing option by Spanish authorities remains low in a sample of MSM recruited in contexts specialized in the diagnosis of HIV and other STIs. Knowledge about self-testing needs to be promoted drastically as a necessary first step to scale up self-testing. Additionally, the cost and distribution methods of self-testing kits need to be taken into account in order to reach socially and economically less favored MSM as well as those who do not live their sexuality in an open manner who, in this study, reported lower knowledge and use.

Supplementary Materials: The following supporting information can be downloaded at: https:// www.mdpi.com/article/10.3390/ijerph19031096/s1, File S1: List of the Collaborators/Membership of the Group.

Author Contributions: Conceptualization, J.H., L.d.1.F., M.-J.B., P.G.d.O. and M.-J.F.; methodology, J.H., J.-M.G., M.-J.B. and P.G.d.O.; software, J.-M.G., J.H. and D.P.; validation, J.-M.G., D.P., J.-N.G.-P. and Methysos Project Group; formal analysis, J.-M.G., J.H. and D.P.; investigation, L.d.l.F., J.-M.G., J.H., M.-J.F., D.P., J.-N.G.-P., P.G.d.O. and M.-J.B.; resources, L.d.l.F., M.-J.B., P.G.d.O. and Methysos Project Group; data curation, J.-M.G., J.H., D.P., J.-N.G.-P. and Methysos Project Group; writingoriginal draft preparation, J.-M.G., J.H. and M.-J.B.; writing-review and editing, J.-M.G., J.H., L.d.l.F., M.-J.B., M.-J.F. and P.G.d.O.; visualization, D.P., M.-J.F. and J.-N.G.-P.; supervision, L.d.l.F., M.-J.B. and P.G.d.O.; project administration, P.G.d.O. and M.-J.B.; funding acquisition, M.-J.B., J.-M.G. and M.-J.F. All authors have read and agreed to the published version of the manuscript.

Funding: This study was supported by Delegación del Gobierno para el Plan Nacional sobre Drogas (20191017) and Convocatoria del Plan de Consolidación de la Investigación del IMIENS (2021). Both funders had no further role in study design, in the collection, analysis, and interpretation of data, in the writing of the report, and in the decision to submit the paper for publication.

Institutional Review Board Statement: The study was conducted according to the guidelines of the Declaration of Helsinki and was approved by the ethical committee of investigation and animal welfare of the Instituto de Salud Carlos III (CEI PI 44_2018_subproyecto1-v2 and CEI PI 44_2018_subproyecto2). 
Informed Consent Statement: Informed consent was obtained from all subjects involved in the study.

Data Availability Statement: The datasets used and/or analyzed during the current study are available from the corresponding author on reasonable request.

Acknowledgments: The authors are grateful to Pink Peace whose rapid HIV testing program was responsible for the recruitment of participants in Madrid.

Conflicts of Interest: The authors declare no conflict of interest.

\section{References}

1. Unidad de Vigilancia de VIH y Comportamientos de Riesgo. Vigilancia de VIH y Comportamientos de Riesgo. Vigilancia Epidemiológica del VIH y sida en España 2019: Sistema de Información sobre Nuevos Diagnósticos de VIH y Registro Nacional de Casos de Sida. In Plan Nacional Sobre el Sida; D.G. de Salud Pública, Calidad e Innovación/Centro Nacional de EpidemiologíaISCIII: Madrid, Spain, 2020. Available online: https:/ / www.mscbs.gob.es/ciudadanos/enfLesiones/enfTransmisibles/sida/ vigilancia/Informe_VIH_SIDA_20201130.pdf (accessed on 15 November 2021).

2. $\quad$ Lundgren, J.D.; Babiker, A.G.; Gordin, F.; Emery, S.; Grund, B.; Sharma, S.; Avihingsanon, A.; Cooper, D.A.; Fätkenheuer, G.; Llibre, J.M.; et al. Initiation of Antiretroviral Therapy in Early Asymptomatic HIV Infection. N. Engl. J. Med. $2015,373,795-807$. [PubMed]

3. Danel, C.; Moh, R.; Gabillard, D.; Badje, A.; Le Carrou, J.; Ouassa, T.; Ouattara, E.; Anzian, A.; Ntakpé, J.B.; Minga, A.; et al. A Trial of Early Antiretrovirals and Isoniazid Preventive Therapy in Africa. N. Engl. J. Med. 2015, 373, 808-822. [PubMed]

4. $\quad$ Rodger, A.J.; Lodwick, R.; Schechter, M.; Deeks, S.; Amin, J.; Gilson, R.; Paredes, R.; Bakowska, E.; Engsig, F.N.; Phillips, A. Mortality in well controlled HIV in the continuous antiretroviral therapy arms of the SMART and ESPRIT trials compared with the general population. AIDS 2013, 27, 973-979. [CrossRef]

5. Cohen, M.S.; Chen, Y.Q.; McCauley, M.; Gamble, T.; Hosseinipour, M.C.; Kumarasamy, N.; Hakim, J.G.; Kumwenda, J.; Grinsztejn, B.; Pilotto, J.H.; et al. Antiretroviral Therapy for the Prevention of HIV-1 Transmission. N. Engl. J. Med. 2016, 375, 830-839. [CrossRef]

6. Rodger, A.J.; Cambiano, V.; Bruun, T.; Vernazza, P.; Collins, S.; van Lunzen, J.; Corbelli, G.M.; Estrada, V.; Geretti, A.M.; Beloukas, A.; et al. Sexual Activity Without Condoms and Risk of HIV Transmission in Serodifferent Couples When the HIV-Positive Partner Is Using Suppressive Antiretroviral Therapy. JAMA 2016, 316, 171-181. [CrossRef] [PubMed]

7. UNAIDS. Understanding Fast-track. In Proceedings of the Accelerating action to end the AIDS epidemic by 2030, Geneva, Switzerland, 15 November 2015. Available online: https:/ / www.unaids.org/sites/default/files/media_asset/201506_JC2743_ Understanding_FastTrack_en.pdf (accessed on 15 November 2015).

8. Diez, M.; Bleda, M.J.; Varela, J.R.; Ordonana, J.; Azpiri, M.A.; Vall, M.; Santos, C.; Viloria, L.; de Armas, C.; Urena, J.M.; et al. Trends in HIV testing, prevalence among first-time testers, and incidence in most-at-risk populations in Spain: The EPI-VIH Study, 2000 to 2009. Eurosurveillance 2014, 19, 20971. [CrossRef] [PubMed]

9. Balbuena, S.F.; Hoyos, J.; Belza, M.J.; Pujol, F.; Álvarez, J.; Zulaica, D.; Zamora, C.; Rifá, B.; García-de-Olalla, P.; Esteso, R.; et al. HIV Rapid Testing Programs in Non-Clinical Settings have the Potential to Constitute a Major Diagnostic Option for MSM in Spain. AIDS Behav. 2017, 21, 525-533. [CrossRef]

10. Fernández-Balbuena, S.; Belza, M.J.; Zulaica, D.; Martinez, J.L.; Marcos, H.; Rifá, B.; Arrillaga, A.; de la Fuente, L.; Hoyos, J. Widening the Access to HIV Testing: The Contribution of Three In-Pharmacy Testing Programmes in Spain. PLoS ONE 2015, 10, e0134631. [CrossRef]

11. The EMIS Network. EMIS-2017: The European Men-Who-Have-Sex-with-Men Internet Survey. Key Findings from 50 Countries. 2019. Available online: https://www.ecdc.europa.eu/sites/default/files/documents/European-MSM-internet-survey-2017 -findings.pdf (accessed on 15 November 2021).

12. European Centre for Disease Prevention and Control. Public Health Guidance on HIV, Hepatitis B and C Testing in the EU/EEA. In An Integrated Approach; ECDC: Stockholm, Sweden, 2018. Available online: https://www.ecdc.europa.eu/sites/default/files/ documents/hiv-hep-testing-guidance_0.pdf (accessed on 15 November 2021).

13. Jakobsen, S.F.; Raben, D.; Sperle, I.; Lazarus, J.V.; James, C.; Mendão, L.; de Wit, J.; Platteau, T.; von Lingen, A.I.; Corbelli, G.M.; et al. Scale-up of HIV self-testing. HIV Med. 2018, 19, e72-e74. [CrossRef]

14. World Health Organization; UNITAID. Market and Technology Landscape: HIV Rapid Diagnostic Tests for Self-Testing; UNITAID: Geneva, Switzerland, 2018. Available online: https:/ / unitaid.org/assets/HIVST-landscape-report.pdf (accessed on 15 November 2021).

15. Boletín Oficial del Estado. Real Decreto 1083/2017, de 29 de Diciembre, por el que se Modifica el Real Decreto 1662/2000, de 29 de Septiembre, Sobre Productos Sanitarios para Diagnóstico «In Vitro», con Objeto de Regular la Venta al Público y la Publicidad de los Productos de Autodiagnóstico para la Detección del VIH; BOE: Madrid, Spain, 2017; pp. 130888-130889. Available online: https:/ / www.boe.es/boe/dias/2017/12/30/pdfs/BOE-A-2017-15858.pdf (accessed on 15 November 2021).

16. World Health Organization. WHO Recommends HIV Self-Testing; World Health Organization: Geneva, Switzerland, 2016. Available online: https:/ / apps.who.int/iris/bitstream/handle/10665/251549/WHO-HIV-2016.21-eng.pdf?sequence=1 (accessed on 15 November 2021).

17. Witzel, T.C.; Rodger, A.J. New initiatives to develop self-testing for HIV. Curr. Opin. Infect. Dis. 2017, 30, 50-57. [CrossRef] 
18. Koutentakis, K.; Hoyos, J.; Rosales-Statkus, M.E.; Guerras, J.M.; Pulido, J.; de la Fuente, L.; Belza, M.J. HIV self-testing in Spain: A valuable testing option for men-who-have-sex-with-men who have never tested for HIV. PLoS ONE 2019, 14, e0210637. [CrossRef] [PubMed]

19. Hoyos, J.; Maté, T.; Guerras, J.M.; Donat, M.; Agustí, C.; Kuske, M.; Fuertes, R.; Chanos, S.; Pichon, F.; Sordo, L.; et al. Preference towards HIV Self-Testing above Other Testing Options in a Sample of Men Who Have Sex with Men from Five European Countries. Int. J. Environ. Res. Public Health 2021, 18, 4804. [CrossRef]

20. McGuire, M.; de Waal, A.; Karellis, A.; Janssen, R.; Engel, N.; Sampath, R.; Carmona, S.; Zwerling, A.A.; Suarez, M.F.; Pai, N.P. HIV self-testing with digital supports as the new paradigm: A systematic review of global evidence (2010-2021). EClinicalMedicine 2021, 39, 101059. [CrossRef] [PubMed]

21. Witzel, T.C.; Eshun-Wilson, I.; Jamil, M.S.; Tilouche, N.; Figueroa, C.; Johnson, C.C.; Reid, D.; Baggaley, R.; Siegfried, N.; Burns, F.M.; et al. Comparing the effects of HIV self-testing to standard HIV testing for key populations: A systematic review and meta-analysis. BMC Med. 2020, 18, 381. [CrossRef] [PubMed]

22. Belza, M.J.; Figueroa, C.; Rosales-Statkus, M.E.; Ruiz, M.; Vallejo, F.; de la Fuente, L. Low knowledge and anecdotal use of unauthorized online HIV self-test kits among attendees at a street-based HIV rapid testing programme in Spain. Int. J. Infect. Dis. 2014, 25, 196-200. [CrossRef] [PubMed]

23. Koutentakis, K.; Rosales-Statkus, M.E.; Hoyos, J.; Fernández-Balbuena, S.; Ruiz, M.; Agustí, C.; de la Fuente, L.; Belza, M.J Knowledge and use of unauthorized HIV self-test kits among men who have sex with men in Spain, following approval of an over-the-counter self-test in the U.S: A cross-sectional study. BMC Public Health 2016, 16, 532. [CrossRef]

24. Hoyos, J.; Belza, M.J.; Fernández, S.; Perez, S.; de la Fuente, L.; Arranz, B.; Cabeza, C.; Burgos, M.C.; Guerras, J.M.; Maté, T.; et al. Euro HIV EDAT Project. In KAB/P Study on the Implementation of Innovative HIV Testing Strategies: Main Results of a Study Conducted among MSM and Stakeholders; Euro HIV EDAT Project; European Union: Maastricht, The Netherlands, 2017. Available online: https://eurohivedat.eu/arxius/ehe_docsmenu_docsmenu_doc_154-Final_Report_KABP_study_on_ the_implementation_of_innovative_HIV_testing_strategies.pdf (accessed on 25 November 2021).

25. Greacen, T.; Friboulet, D.; Fugon, L.; Hefez, S.; Lorente, N.; Spire, B. Access to and use of unauthorised online HIV self-tests by internet-using French-speaking men who have sex with men. Sex. Transm. Infect. 2012, 88, 368-374. [CrossRef] [PubMed]

26. Devez, P.E.; Epaulard, O. Perceptions of and intentions to use a recently introduced blood-based HIV self-test in France. AIDS Care 2018, 30, 1223-1227. [CrossRef]

27. Instituto Nacional de Estadística. España Municipal 2021; INE: Madrid, Spain, 2021. Available online: https://www.ine.es/ infografias/infografia_padron.pdf (accessed on 15 November 2021).

28. Barros, A.J.; Hirakata, V.N. Alternatives for logistic regression in cross-sectional studies: An empirical comparison of models that directly estimate the prevalence ratio. BMC Med. Res. Methodol. 2003, 3, 21. [CrossRef] [PubMed]

29. Espelt, A.; Marí-Dell'Olmo, M.; Penelo, E.; Bosque-Prous, M. Applied Prevalence Ratio estimation with different Regression models: An example from a cross-national study on substance use research. Adicciones 2016, 29, 105-112. [CrossRef] [PubMed]

30. Hoyos, J.; Guerras, J.M.; Maté, T.; Agustí, C.; Fernández-López, L.; Fuente, L.; Belza, M.J. Opinions Towards Key Operational Aspects for the Implementation of HIV Self-Testing in Spain: A Comparison between Stakeholders and Potential Users. Int. J. Environ. Res. Public Health 2021, 18, 1428. [CrossRef] [PubMed]

31. den Daas, C.; Doppen, M.; Schmidt, A.J.; Op de Coul, E. Determinants of never having tested for HIV among MSM in the Netherlands. BMJ Open 2016, 6, e009480. [CrossRef] [PubMed]

32. Prati, G.; Breveglieri, M.; Lelleri, R.; Furegato, M.; Gios, L.; Pietrantoni, L. Psychosocial correlates of HIV testing among men who have sex with men in Italy: A cross-sectional study. Int. J. STD AIDS 2014, 25, 496-503. [CrossRef] [PubMed]

33. Witzel, T.C.; Melendez-Torres, G.J.; Hickson, F.; Weatherburn, P. HIV testing history and preferences for future tests among gay men, bisexual men and other MSM in England: Results from a cross-sectional study. BMJ Open 2016, 6, e011372. [CrossRef]

34. Bjørnshagen, V.; Moseng, B.U.; Ugreninov, E. Who Do You Reach? A Norwegian Pilot Project on HIV Self-Testing that Targeted Men Who Have Sex with Men. AIDS Behav. 2020, 24, 568-579. [CrossRef]

35. Eshun-Wilson, I.; Jamil, M.S.; Witzel, T.C.; Glidded, D.V.; Johnson, C.; Le Trouneau, N.; Ford, N.; McGee, K.; Kemp, C.; Baral, S.; et al. A Systematic Review and Network Meta-analyses to Assess the Effectiveness of Human Immunodeficiency Virus (HIV) Self-testing Distribution Strategies. Clin. Infect. Dis. Off. Publ. Infect. Dis. Soc. Am. 2021, 73, e1018-e1028. [CrossRef]

36. Kelvin, E.A.; Akasreku, B. The Evidence for HIV Self-Testing to Increase HIV Testing Rates and the Implementation Challenges that Remain. Curr. HIV AIDS Rep. 2020, 17, 281-289. [CrossRef]

37. Guerras, J.M.; Hoyos, J.; Agustí, C.; Casabona, J.; Sordo, L.; Pulido, J.; De la Fuente, L.; Belza, M.J.; Grupo de Trabajo Euro Hiv Edat. Substance use in Sexual Context among Spanish Resident Men who have Sex with Men. Adicciones 2020, 1371. [CrossRef] 